\title{
How Students' Understand the Linear Equation and Inequalities (Factual, Conceptual, Procedural Knowledge)
}

\author{
A. Sri Mardiyanti Syam ${ }^{1}$ \\ ${ }^{I}$ Faculty of Tarbiyah, Institut Agama Islam Negeri Bone, Jl. HosCokroaminoto, Bone, Indonesia \\ srimardiyanti@iain-bone.ac.id
}

Keywords: $\quad$ Students Understanding, Factual Knowledge, Conceptual Knowledge, Procedural Knowledge, Algebra

Abstract: The research objective was to describe the students' understanding on the linear equation and inequalities related to factual, conceptual and procedural knowledge. This study was qualitative. The focus of the research is to describe the students' understanding of factual knowledge, conceptual and procedural.The main instrument was the researcher itself, and other instruments were a diagnostic test to determine the subject and diagnose the types of students' understanding, and interview guideline. The subjects of this research were three students of grade VIII junior High School in Bone who were selected based on the diagnostic test results with high, medium, and low criteria. The results showed: (1) The students' understanding of factual knowledge on linear equation and inequalities in one variable was able from one form into another form that can be viewed from the chosen three subjects that can mention the given coefficients, variables, and constants, can express the equation became an open sentence or otherwise can express a sentence became equation. (2)The students' understanding of conceptual knowledge on linear equation and inequalities in one variable was able to change from one form into another form and find an example or illustration of the concept or principle. Whereas the understanding of conceptual knowledge was able to determines something that belongs to a category and only be done by the high subject and moderate subject. (3) The students' understanding of procedural knowledge on linear equation and inequalities in one variable was able to change from one form into another form and determine something in a category can only be done by the high subject and moderate subject.

\section{INTRODUCTION}

In mathematics learning, conceptual understanding is the ability that should mastered by the students as a basis for further learning. As stated in the Minister of National Education Regulation of Indonesian Republic No. 58 of 2014 that one of the objectives of mathematics learning is to understand the concept of mathematics, explaining the interconnection between concepts and apply the concept flexibly, accurately, efficiently and appropriately in the problem-solving. By understanding the concepts in the learning mathematics, the students are expected to be able to connect and apply it in everyday life. Thus, what they learn will be more meaningful.
Understanding is someone's ability to understand or comprehend something after knowing and remembering something [1]. Understanding is the cognitive activity of a person in connecting an object to another object [2]. Students can be said to be able to understand when they can connect their new knowledge and old knowledge [3]. It can be said that understanding is one's ability to connect appropriate knowledge schemes into the scheme he has acquired from previous learning experiences.

In relation to students' understanding of mathematical objects namely concept, fact, procedure and principle [4], in Indonesia over $80 \%$ of students do not like to study math at school. This happens because students think that mathematics is difficult in term of the difficulty in calculating, 
understanding, and solving math problems. Thus, they do not like math [5]. In addition, the mathematics that uses many symbols and terms which makes students feel more confused in interpreting them. Most students also learn without knowing what they are learning because they are rarely asked to communicate what they have learned.Based on data from TIMSS in 2011 shows that Indonesia's score is still far below the average international score. This proves that students' concept of understanding ability is still weak, especially in non-routine matters [6].

Algebra is one of the concepts considered to be very difficult to understand by the students [7]. The completion of the algebraic form is understood by students in relation to its abstract rules. The reason is that the concept of algebra is often presented in the abstract form during the classroom learning. This difficulty occurs because the ability of students in understanding abstract mathematical concepts is very limited. In addition, it is also often found a misconception that inhibits students' understanding of mathematical concepts. Student misconceptions about algebraic concepts occur in the negativity, variables, divisions, and functions, as well as similarities and inequalities[8] [9] [10] [11].

The ability to understand a subject in the mathematics field requires the mastery of factual, conceptual, and procedural knowledge. These three knowledges are related to the completion of mathematics problem. Thus, factual, conceptual and procedural knowledge is the important aspect that must be possessed by the students in order to obtain good understanding in learning mathematics.

The research conducted by Booth (2017) finds that the students' conceptual and procedural understanding of algebra material is still very low [7]. In fact, in the matter of equations and linear inequalities of one variable shows very low results as evidenced by the inability of students to answer the problem with the right argument [12]. This is in line with the research conducted by Hidayati (2010) which produces difficulties experienced by grade VIII students in solving algebra problems related to high categorical concepts and principles, especially when students have to present a concept into the picture [13].

Based on the results of an interview with mathematics teachers in junior high school 1 Tonra, it is obtained the information that the students' mathematical understanding is still very low. Most of the students cannot retell the concept that has been explained. Furthermore, most of the students are not able to make mathematical model form the given narrative problem. Most of the students are unable to use certain concept or procedure in solving the given question. This eventually affects the inability to conclude the material they have learned by the end of the lesson. One of the teaching materials that are still quite difficult to understand students is the equation and linear inequalities one variable (PLSV), especially in the use or determination of symbols used as variables such as: "y number of days in a week". In the last three years, the results of student's daily repetition of the material of Equations and Linear Inequalities One Variable is very low. Almost $75 \%$ of the students did not reach the established KKM that is 65 . The teacher suspects this is because the students still lack students understanding of the material.

Based on the above explanation and to understand the case deeply, a research is required to investigate the students' understanding based on factual, conceptual and procedural knowledge.

\section{RESEARCH METHODS}

This research is a descriptive research with a qualitative approach. This research was conducted at Junior High School class VIII. The subjects of this study were three students selected by purposive with criterion-based selection [14]. The procedure of choosing a subject is: (a) giving a test of the ability of equations and linear inequalities of one variable in class VII which has been selected; (b) analyzing students' work results from the tests of the ability of equations and linear inequalities of one variable: (c) Grouping students into high-ability student category $(80 \leq \mathrm{x} \leq 100)$, moderate ability $(65 \leq \mathrm{x}<80)$, and low ability $(x<65)$, where $x$ is the value of the diagnostic test of the material ability of the equation and the linear inequalities of one variable: (e) Then selecting three students to be subjected to the study of three groups with high, medium and low criteria.

Instruments used in this research are diagnostic tests to define the subject and diagnose students' understanding of factual, conceptual and procedural knowledge, and interview guides to delve deeper into how students understand the factual, conceptual, and procedural knowledge with the following indicators of understanding : (1) change one form to another form; (2) find a specific example or 
Table 1. Excerpts of interviews with the high subject (HS)

something that belongs to a category; (4) abstracting common themes or key point; (5) illustrates the logical conclusion of the information presented; (6) looking for a relationship between two ideas, objects or similar things; (7) construct a causal model of a system. The analysis of this research is carried out by several stages starting by collecting data in the form of test results and interview results. After the data are collected, data reduction, data presentation, and conclusion are made.

\section{RESULTS AND DISCUSSION}

\subsection{The Students' Understanding Of Factual Knowledge \\ 3.1.1 The High Subject's Understanding Of Factual Knowledge}

The High Subjects' understanding (HS) related to factual knowledge was changed one form to another form. It was shown from the subject's ability to translate the given question. On the question about determining the coefficients, variables, and constants of an algebraic form based on the results of the task and the interview subject can correctly answer the question to understand the facts that contained on the question that there is a form of algebra required to determine the coefficients, variables, and constants. This shows the high subject has relevant knowledge related to the given algebraic form including the numbers and positive and negative values before determining the things that requested by the question.

Subjects had no difficulty when determining the things that were requested in the question. It shows the knowledge related to the algebra has been attached to the subject's mind that later became the basis for the work on the problems. Proofed by an interview HS-007 to HS-009 that indicates the subject was able to give a definition related coefficients, variables, and constants.

Similarly, the question on number two, the subject did not experience difficulties when asked to make the equation from the given statement. It shows students understand what the question mean equation.

\begin{tabular}{|c|c|c|}
\hline Code & $\mathbf{Q} / \mathbf{A}$ & Description \\
\hline Q-007 & $\mathbf{Q}$ & What is the coefficient? \\
\hline HS-007 & A & $\begin{array}{l}\text { The coefficient is an existing number } \\
\text { of variables }\end{array}$ \\
\hline Q-008 & $\mathbf{Q}$ & How about the Variabel? \\
\hline HS-008 & A & $\begin{array}{l}\text { The variable is a symbol used to } \\
\text { replace an unknown number of true } \\
\text { or false values. }\end{array}$ \\
\hline Q-009 & Q & constants, what does it mean? \\
\hline HS-009 & A & Fixed numbers, no variables. \\
\hline
\end{tabular}

The subject has also been able to answer the questions about making statement from the given linear equation well. The subject was changed the given linear equation $(x-7=12)$ into corresponding open sentence (Ita's book is borrowed 7 pieces by difa now it's 12 remaining books). In this question, the value $(-7)$ of the subject has made became borrowed 7 pieces, the use of the word "borrow" shows the factual knowledge of the subject that borrow shows means less (minus). That fact shows the subject has used factual knowledge to answer questions and an appropriate understanding indicator is a change one form to another form.

\subsubsection{The Moderate Subject's Understanding of Factual Knowledge}

The Moderate Subject's (MS) understanding related to factual knowledge that the author found was changed one form to another form. It was shown from the subject's ability to translate the given question.

Based on the results of the task and the interview subject can correctly answer the question to understand the facts that contained on the question that there is a form of algebra required to determine the coefficients, variables, and constants. This shows the moderate subject has relevant knowledge related to the given algebraic form including the numbers and positive and negative values before determining the things that requested by the question.

Subjects had no difficulty when determining the things that were requested in the question. It shows the knowledge related to the algebra has been attached to the subject's mind that later became the 
basis for the work on the problems. Proofed by an interview MS-007 to MS-009 that indicates the subject was able to give a definition related coefficients, variables, and constants.

Table 2. Excerpts of interviews theModerate subject (MS)

\begin{tabular}{ccc}
\hline Code & Q/A & \multicolumn{1}{c}{ Description } \\
\hline Q-007 & Q & What is the coefficient? \\
MS-007 & A & $\begin{array}{l}\text { The coefficient is the number followed } \\
\text { by the variable }\end{array}$ \\
Q-008 & Q & How about the Variabel? \\
MS-008 & A & $\begin{array}{l}\text { Em, Variable is the symbol used to } \\
\text { replace something }\end{array}$ \\
Q-009 & Q & constants, what does it mean? \\
MS-009 & A & Number not followed by variable \\
\hline
\end{tabular}

The subject did not experience difficulties when asked to make the equation from the given statement. It shows students understand what the question mean equation.

The subject has also been able to answer the questions well about changing the given linear equation into open sentences. The subject was changed the given linear equation $(x-7=12)$ into corresponding open sentence (Yesterday I lost 7 marbles, now my marbles 12 remain.). In this question, the value (-7) of the subject has made became lost 7, the use of the word "lost" shows the factual knowledge of the subject that lost means less (minus). That fact shows the subject has used factual knowledge to answer questions and an appropriate understanding indicator is a change one form to another form.

\subsubsection{The low Subject's Understanding of Factual Knowledge}

The Low Subject's (LS) understanding related to factual knowledge that the author found was changed one form to another form. It was shown from the subject's ability to translate the given question.

On the question, no 1 , based on the results of the task and the interview subject can correctly answer the question to understand the facts that contained on the question that there is a form of algebra required to determine the coefficients, variables, and constants. This shows the low subject has relevant knowledge related to the given algebraic form including the numbers and positive and negative values before determining the things that requested by the question.

Subjects had no difficulty when determining the things that were requested in the question. It shows the knowledge related to the algebra has been attached to the subject's mind that later became the basis for the work on the problems. Proofed by an interview LS-007 to LS-009 that indicates the subject was able to give a definition related coefficients, variables, and constants.

Table 3. Excerpts of interviews with theLow subject (LS)

\begin{tabular}{ccc}
\hline Code & Q/A & Description \\
\hline Q-007 & Q & What is the coefficient? \\
LS-007 & A & The numbers in front of $x$ \\
& & \\
Q-008 & Q & How about the Variable? \\
LS-008 & A & letters or symbols used. Like this x or y \\
Q-009 & Q & constants, what does it mean? \\
LS-009 & A & own numbers, no variables \\
\hline
\end{tabular}

Similarly, the question on number two, the subject did not experience difficulties when asked to make the equation from the given statement. It shows students understand what the question mean equation. The subject has also been able to answer the questions well about changing the given linear equation into open sentences. The subject was changed the given linear equation $(x-7=12)$ into corresponding open sentence (I lost 7 candies, now12 remain). In this question, the value $(-7)$ of a subject has made became lost 7 candies, the use of the word "lost" shows the factual knowledge of the subject that lost means minus. That fact shows the subject has used factual knowledge to answer questions and an appropriate understanding indicator is a change one form to another form. 


\subsubsection{The Moderate Subject's Understanding of Conceptual Knowledge}

\subsubsection{The High Subject's Understanding of Conceptual Knowledge}

The subject's understanding related to conceptual knowledge that the author found were: (1) changed one form to another form, (2) Find an example or illustration of the concept, (3) Determine something that belongs to a category and (4) Find a connection between two objects/ similar things.

High Subject has an ability to express given sentence into linear equation or conversely. The high subject has been able to convert word problem into mathematical sentence in this case related to linear equation or inequalities in one variable. The high subject has been able to expressed set solution from inequalities form to graphic form

The Subjects has an ability to find an example of the concept. This indicator is shown by the subject's ability in giving definitions of the coefficients, variables and constant. Subject mentions high coefficient definition as containing variable numbers. The variable being defined as a symbol that is used to replace a number of unknown values was right or wrong. Although, constant as a number that does not contain a variable. This shows the high subject can make illustration of a concept. In other side, the high subject can express example of an equation into an open sentence form. And also be able to illustrate example of a graphic solution from inequalities with one of the ends was open.

Based on the five given equations, the subject was also able to distinguish between examples and non-examples of linear inequalities in one variable. . Understanding of the concept of inequalities was also shown by mentioning the characteristics of an example of a linear inequalities in one variable. "there is a sign less than, more than, less than or equal to, more than or equal to." In the next excerpt high subject was able to mention properly about the part that was not intended. For example, part e. on a matter which is a linear equation and part a on questions that the two variable linear inequalities.

The Subject has an ability to connect her knowledge related square circumference formula that has been gotten since at elementary school (ST024) with her knowledge related to algebraic operation to solve the question number six.
The moderate subject's understanding related to conceptual knowledge that the author found were:(1) changed one form to another form, (2) Find an example or illustration of the concept, (3) Determine something that belongs to a category and (4) Find a connection between two objects/ similar things.

Moderate subject has an ability to express given sentence into the linear equation or conversely. As shown when answering the question number two and three. On the question number five and six, the high subject has been able to convert a word problem into the mathematical sentence in this case related to linear equation or inequalities in one variable.

Subject mentions high coefficient definition as containing variable numbers. The variable is being defined as a symbol that is used to replace a number of unknown values were right or wrong. Although, constant as a number that does not follow the variable. This shows the high subject can make an illustration of a concept. On the other side, the high subject can express example of an equation into an open sentence form.

Based on five given equations, the subject was also able to distinguish between examples and nonexamples of linear inequalities in one variable. In the next excerpt high subject was able to mention properly about the part that was not intended. For example, part e. on a matter which is a linear equation and part a on questions that the two variable linear inequalities. Besides that, the subject could determine the length of circumference square known by using algebra (linear equation in one variable). The Subjects was also shown the ability to determine the equivalency and solution of linear inequalities in one variable.

Moderate subjects was able to find a connection between two objects/ similar things. This indicator showed in subject ability to connect her knowledge related square circumference formula with her knowledge related to the algebraic operation to solve the question number six.

\subsubsection{The Low Subject's Understanding of Conceptual Knowledge}

The Low subject's understanding related to conceptual knowledge that the author found were: (1) changed one form to another form, (2) Find an example or illustration of the concept, (3) Determine something that belongs to a category. 
The Subject explains the reason to subtract the same number both sides in algebraic operation as seen in excerpt HS-020. The subject also explains the reason for solving the question by multiplying each side by 4 as seen on excerpt HS-036. Subject explained the step to simplify the equation by subtracting each side by $32 \mathrm{x}$ as seen on excerpt HS037. Subjects also describe the set of settlement on an inequality that is in the picture to the chart include $\{0,1,2,3,4,5,6\}$ so that the graph is open at number 7 because of the use of the symbol "less than".

\subsubsection{The Moderate Subject's Understanding of Procedural Knowledge} equation into an open sentence form.

The indicator of determine something that belongs to a category showed when low subjects showed the subject are able to classify linear inequalities form in one variable through marked (LS-014). From five given equations, the subject was also able to distinguish between examples and non-examples of linear inequalities in one variable. In the next excerpt high subject was able to mention properly about the part that was not intended. For example, part e. on a matter which is a linear equation and part a on questions that the two variable linear inequalities.

\subsection{The Students' Understanding of Procedural Knowledge}

\subsubsection{The High Subject's Understanding of Procedural Knowledge}

The high subject's understanding related to procedural knowledge that the author found was construct models of causality of a system This indicator showed in the subject's ability to explain step by step solution to answer the given question given sentence into a linear equation or conversely. As in number two, the subject let the age of Fia as $x$ then make the equation to $2(x+10)=3 x$. The subject was also able to explain the uses of parenthesis (HS$013)$. From the $(x+10)$, subject represent $x$ as the age of Fia, so that $(x+10)$ is the age of Fia in the coming ten years. It also looks at the question number four, subject determine the length side of the square by expressing it into a linear equation. Subject let the length of the square into variable a then operate it (HS-023). procedural knowledge that the author found was construct models of causality of a system. This indicator showed in the subject's ability to explain step by step solution to answer the given question given sentence into a linear equation or conversely. As in number two, the subject let the age of Fia as $x$ then make the equation to $2(x+10)=3 x$, and also let Arif's marble as $\mathrm{x}$ then make it the equation $2 x+2=x-8$. It also shown at the question number six, subject determined the length side of the square by expressing it into the linear equation. Subject let the length of the square into variable $\mathrm{x}$ then operate it (MS-020).

Subject explained the reason to subtract the same number both sides in algebraic operation as seen in excerpt MS-017. The subject also explained the reason for solving the question by multiplying each side by 4 as seen on excerpt MS-025. Subject explained the step to simplify the equation by subtracting each side by $32 \mathrm{x}$ as seen on excerpt MS026.

\subsubsection{The Low Subject's Understanding of Procedural Knowledge}

This indicator showed the subject's ability to explain step by step solution to answer the given question given sentence into a linear equation or conversely. As in number two, the subject let the age of Fia as $x$ then make the equation to $2(x+10)=3 x$ and let Arif's marbles as $x$ then make the equation $2 x+2=x$ 8 . This indicator is visible, but very weak because of several exposure-related subject matter that will
The moderate subject's understanding related to 
Falkner, K.P., Levi, L., \& Carpenter, T.P. (1999). Children's understanding of equality: A foundation for algebra. Teaching children mathematics, 6 (4), 232. doing the subject, the subject cannot explain the reasons for the measures taken. This indicates that students can just do without knowing the reason for its use. As seen in excerpts LS-018 until LS-020. The Subject answered it correctly, but when asking why it must subtract 5, Subject responds it "that's what I learned". It shows that subject did not understand the use of the procedure to answer the question.

\section{CONCLUSION}

The students' understanding of factual knowledge on linear equation and inequalities in one variable was able from one form into another form that can be viewed from the chosen three subjects that can mention the given coefficients, variables, and constants, can express the equation became an open sentence or otherwise can express a sentence became equation. The students' understanding of conceptual knowledge on linear equation and inequalities in one variable was able to change from one form into another form and find an example or illustration of the concept or principle. Whereas the understanding of conceptual knowledge was able to determine something that belongs to a category and only is done by the high subject and moderate subject. The students' understanding of procedural knowledge on linear equation and inequalities in one variable was able to change from one form into another form and determine something in a category can only be done by the high subject and moderate subject.

\section{REFERENCES}

Anderson, Lorinet all. (2010). A Taxonomy for learning, teaching dan Assessing: A Revision of Bloom's Taxonomy of Educational Objectives. Yogyakarta: Pustaka Pelajar.

Baroudi, Z. (2006). Easing Student's Transition to Algebra. Australian Mathematics Teacher, 62 (2), 2833.

Bloom, Benyamin S. (1979). Taxonomy of Educational Objectives (The Classification of Educational Goals) Handbook 1 Cognitive Domain. London: Longman Group Ltd.

Booth, J.L., McGinn, K.M., Barbieri, C., and Young, L.K. (2017). Misconceptions and Learning Algebra. Springer, 63-78.
Hidayati, F. (2011). Kajian Kesulitan Belajar Siswa Kelas VII SMP Negeri 16 Yogyakarta Dalam Mempelajari Aljabar (Doctoral dissertation, UNY).

Hudojo, H. (1988). Mengajar belajar matematika. Jakarta: Departemen Pendidikan dan Kebudayaan.

Le Compte, M.D., and Goetz, J.P. (1982). Problems of reliability and validity in ethnographic research. Review of educational research, 52 (1), 3160.

Lin, C.Y., Ko, Y.Y., and Kuo, Y.C. (2014). Changes in pre-service teachers' algebraic misconceptions by using computer-assisted instruction. The International Journal for Technology in Mathematics Education, 21 (3), 89-102.

Sierpinska, A. (2005). On practical and theoretical thinking and other false dichotomies in mathematics education. Springer, 117-135.

Soedjadi, R. (2000). Nuansa kurikulum matematika sekolah di Indonesia. Dalam Majalah Ilmiah Himpunan Matematika Indonesia. Prosiding Konferensi Nasional Matematika X ITB.

Soro, S., Maarif, S., Kurniawan, Y., and Raditya, A. (2018). Dienes AEM as an alternative mathematics understanding of algebra concept. Journal of Physics: Conference Series, 948 (1).

Suratman, D. (2012). Pemahaman Konseptual dan Pengetahuan Prosedural Materi Pertidaksamaan Linear Satu Variabel Siswa Kelas VII SMP (Studi Kasus di Mts. Ushuluddin Singkawang. Jurnal Cakrawala Kependidikan, 9 (2).

Susanto, E., and Retnawati, H. (2016). Perangkat pembelajaran matematika bercirikan PBL untuk mengembangkan HOTS siswa SMA. Jurnal Riset Pendidikan Matematika, 3 (2), 189-197.

Van Dooren, W., Verschaffel, L., and Onghena, P. (2002). The impact of preservice teachers' content knowledge on their evaluation of students' strategies for solving arithmetic and algebra word problems. Journal for Research in mathematics education, 319-351. teaching aid to enhance Indonesian students' 